\title{
Usutu Virus Epizootic in Belgium in 2017 and 2018: Evidence of Virus Endemization and Ongoing Introduction Events
}

\author{
Emna Benzarti,, Michaël Sarlet, ${ }^{1}$ Mathieu Franssen, ${ }^{1}$ Daniel Cadar, ${ }^{2}$ Jonas Schmidt-Chanasit,, \\ Jose Felipe Rivas, ${ }^{1}$ Annick Linden, ${ }^{1}$ Daniel Desmecht, ${ }^{1}$ and Mutien Garigliany ${ }^{1}$
}

\begin{abstract}
Wildlife surveillance allowed the monitoring of the zoonotic mosquito-borne Usutu virus (USUV) in birds and bats (Pipistrellus pipistrellus) in southern Belgium in 2017 and 2018. USUV-RNA was detected in 69 birds (of 253) from 15 species, among which 7 species had not previously been reported to be susceptible to the infection. Similarly, 2 bats (of 10) were detected positive by reverse transcriptase quantitative polymerase chain reaction (RT-qPCR). USUV-associated lesions were mainly found in Eurasian Blackbirds (Turdus merula), in which USUV antigens were demonstrated by immunohistochemistry in the brain, heart, liver, kidney, intestine, and lung. Partial nonstructural protein 5 gene-based phylogenetic analysis showed several identical or closely related strains from 2016, 2017, and 2018 clustering together within Europe 3 or Africa 3 lineages. Further, one USUV strain detected in a common chaffinch (Fringilla coelebs) manifested a close genetic relationship with the European 1 strains circulating in Hungary and Austria. Our data provide evidence of USUV endemization in southern Belgium in local birds and bats, extension of the host range of the virus and ongoing virus introduction from abroad, likely by migratory birds. Our results highlight the need for vigilance in the forthcoming years toward new virus-associated outbreaks in birds and possible human infections in Belgium.
\end{abstract}

Keywords: Usutu virus, Belgium, wild birds, monitoring

\section{Introduction}

$\mathbf{U}$ SUTU VIRUS (USUV) Is a member of the Japanese encephalitis serocomplex within the family Flaviviridae (Kuno et al. 1998). Previously distributed in the African continent (Nikolay et al. 2011), USUV has expanded to Europe (Weissenböck et al. 2002, 2013, Bakonyi et al. 2007, Jöst et al. 2011, Garigliany et al. 2014, Lecollinet et al. 2016) and to the middle east (Mannasse et al. 2017). It is transmitted through the bites of adult ornithophilic mosquitoes (Eiden et al. 2018) to avian hosts, which can show different clinical forms of infection according to the species, ranging from unapparent portage to severe neurological disease and death, which often occurs in blackbirds (Turdus merula) (Benzarti et al. 2019). Other animals, including rodents (shrews) (Diagne et al. 2019), dogs (Durand et al. 2016), bats (Cadar et al. 2014), red deer (García-bocanegra et al. 2016), and equids (Hassine et al. 2014), can be naturally infected with the virus, without reports of associated pathogenicity. The zoonotic potential of USUV, initially observed in Africa (Nikolay et al. 2011), has been recently documented in Europe by the presence of viral RNA or antibodies against the virus in blood donor samples (Pierro et al. 2013, Bakonyi et al. 2017b, Percivalle et al. 2017). Besides, similarly to its close relative West Nile virus (WNV), USUV was shown to cause neurological disorders in both immunocompromised (Cavrini et al. 2009, Pecorari et al. 2009, Kaic et al. 2014) and immunocompetent humans (Kaic et al. 2014, Simonin et al. 2018) and, thus, constitutes a growing source of public health concern.

In Belgium, USUV infection was first detected in the Meuse Valley in a captive Eurasian bullfinch (Pyrrhula pyrrhula) and in a wild great spotted woodpecker (Dendrocopos major), both with neurological signs, in 2012 (Garigliany et al. 2014). Four years later, high bird mortalities linked to

\footnotetext{
${ }^{1}$ Fundamental and Applied Research for Animals \& Health (FARAH), Faculty of Veterinary Medicine, University of Liège, Liège, Belgium.

${ }^{2}$ Bernhard Nocht Institute for Tropical Medicine, WHO Collaborating Centre for Arbovirus and Haemorrhagic Fever Reference and Research, Hamburg, Germany.

${ }^{3}$ Faculty of Mathematics, Informatics and Natural Sciences, University of Hamburg, Hamburg, Germany.
} 
Table 1. Virological and Immunohistochemical Findings in Birds Examined for UsUTU Virus Infection in Southern Belgium in 2017 AND 2018

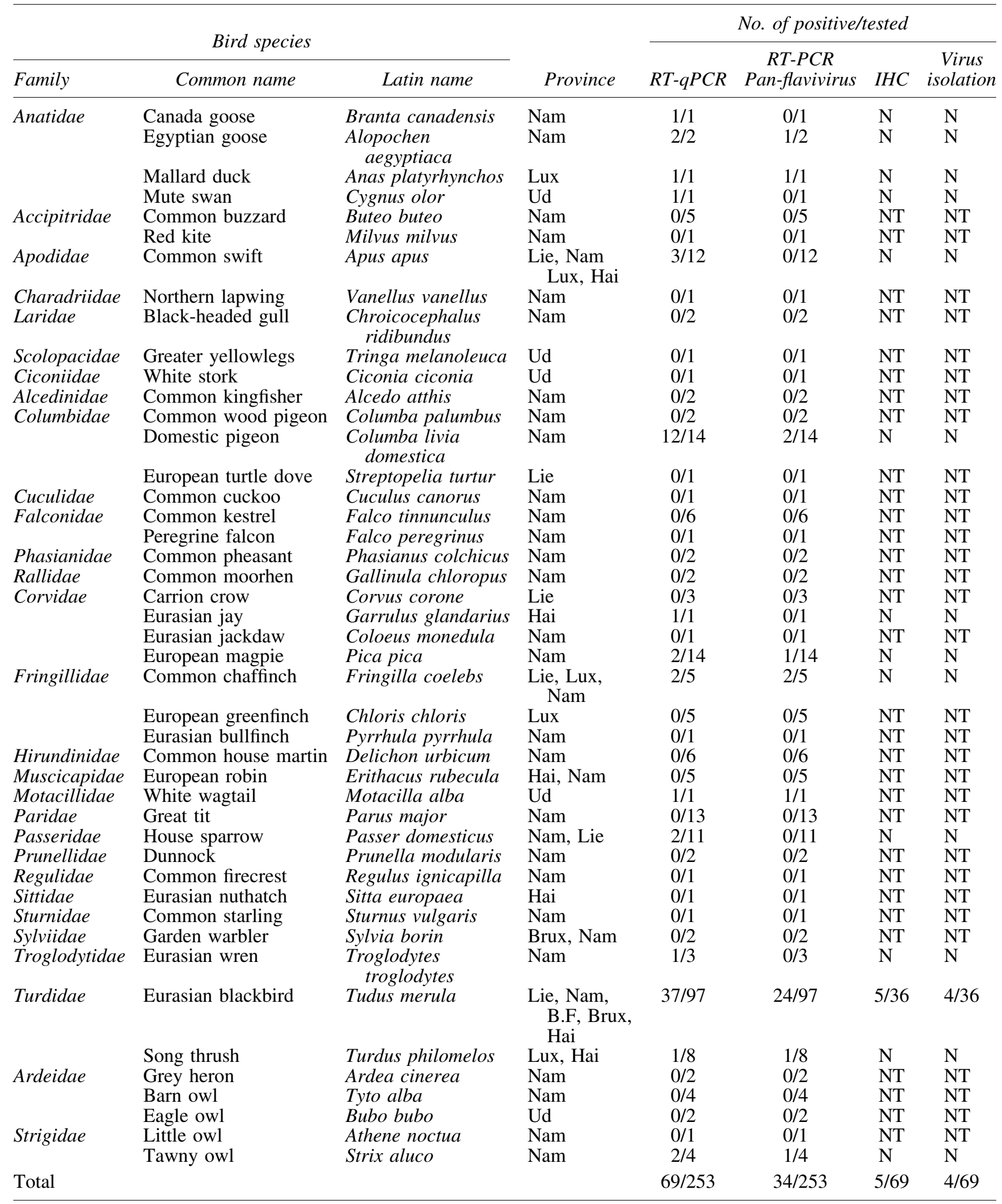

B.F, Brabant Flamand; Brux, Bruxelles; Hai, Hainaut; IHC, immunohistochemistry; Lie, Liège; Lux, Luxembourg; N, negative; Nam, Namur; NT, not tested; RT-qPCR, reverse transcriptase quantitative polymerase chain reaction; Ud, undetermined. 
USUV infection were documented all over the country (Cadar et al. 2016, Borm et al. 2017, Garigliany et al. 2017, Rouffaer et al. 2018), underlining the need for vigilance facing the reemergence and rapid spread of this virus.

Here, we report the findings of USUV dead bird surveillance in 2017 and 2018 in southern Belgium, which was implemented in 2016 after a massive blackbird die-off in this area (Cadar et al. 2016). The passive surveillance also involved pipistrelle bats (Pipistrellus pipistrellus) and aimed (1) to provide up-to-date information about the virus activity in the surveilled zone, (2) to explore the host range of USUV among local bird species, (3) to investigate USUV infection in pipistrelle bats, and (4) to gather insights into the phylogenetic relationship between the circulating strains.

\section{Materials and Methods}

\section{Sample collection and necropsy}

Dead wild birds and bats were submitted for laboratory investigations through the Surveillance Network for Wildlife Diseases of the Veterinary Faculty of Liège, by the centers for the revalidation of animal species living in the wild (CREAVES) in Temploux and Namur and by cooperative citizens who were media solicited to submit dead birds and/or bats to the nearest collection centers.

\section{Detection and isolation of USUV}

Brain and liver samples from dead birds and pipistrelle bats were collected and used for the detection of USUV RNA using reverse transcriptase quantitative polymerase chain reaction (RT-qPCR). Total RNA extraction was conducted as described in Garigliany et al. (2017). USUV-specific RTqPCR was performed using the protocol described by Jöst et al. (2011). Extracted RNA samples were further analyzed for the presence of flavivirus RNA using a modified panflavivirus reverse transcription PCR targeting a segment of

\section{A}
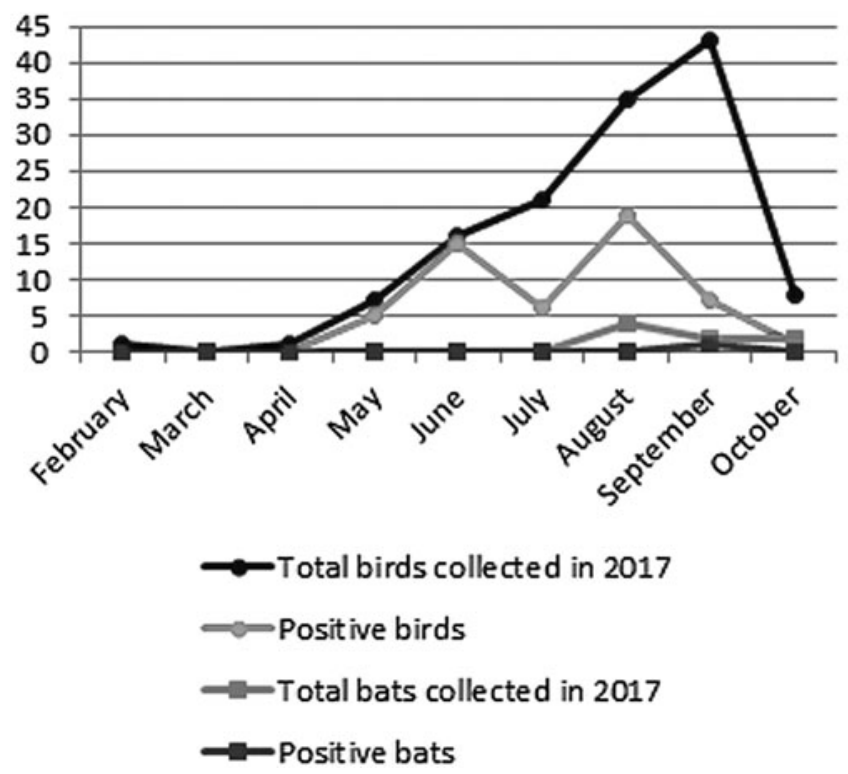

the nonstructural protein 5 (NS5) gene (Becker et al. 2012). Fresh or frozen brain and liver homogenates of wild birds, which were diagnosed USUV positive by RT-qPCR, were subjected to virus isolation in African green monkey kidney cells (Vero, American Type Culture Collection, CCL-81), as described in Savini et al. (2011).

At necropsy, a macroscopic lesion score was established for each case for hepatomegaly and splenomegaly, both considered as typical lesions in case of USUV infection ( 0 : absence of hypertrophy, 1: slight hypertrophy, 2: moderate hypertrophy, 3: severe hypertrophy). Liver, brain, spleen, kidney, heart, and lung samples were collected for histological and immunohistochemical analyses. Tissue samples were fixed in $4 \%$ neutral buffered formalin. After embedding in paraffin wax, tissue sections were stained with hematoxylin and eosin and examined microscopically.

Microscopic scores were assigned for each tissue corresponding to RT-qPCR-positive birds based on the presence of inflammation, necrosis, or hemorrhage (0: absent, 1 : mild, 2: moderate, 3: severe) in the collected organs. Then, the difference between the cycle threshold $(\mathrm{Ct})$ of the sample and the corresponding $\mathrm{Ct}$ value of the messenger RNA of betaactin $(\Delta \mathrm{Ct})$ was calculated to determine the coefficient of correlation $\left(R^{2}\right)$ between the relative amounts of viral genome to both macroscopic and microscopic lesion scores assigned to each of the positive cases.

Paraffin-embedded sections from positive birds were subjected, after dewaxing and rehydration, to immunohistochemistry (IHC) as described in Garigliany et al. (2017) using the monoclonal anti-E protein 4E9 antibody at a 1/200 dilution.

\section{Genetic characterization of the detected USUV strains}

To investigate the phylogenetic relatedness between the circulating Belgian strains in 2017 and 2018 and those available in databases, partial NS5 gene sequences were aligned using ClustalW implemented in Geneious 10.2.3 (Biomatters, New

B
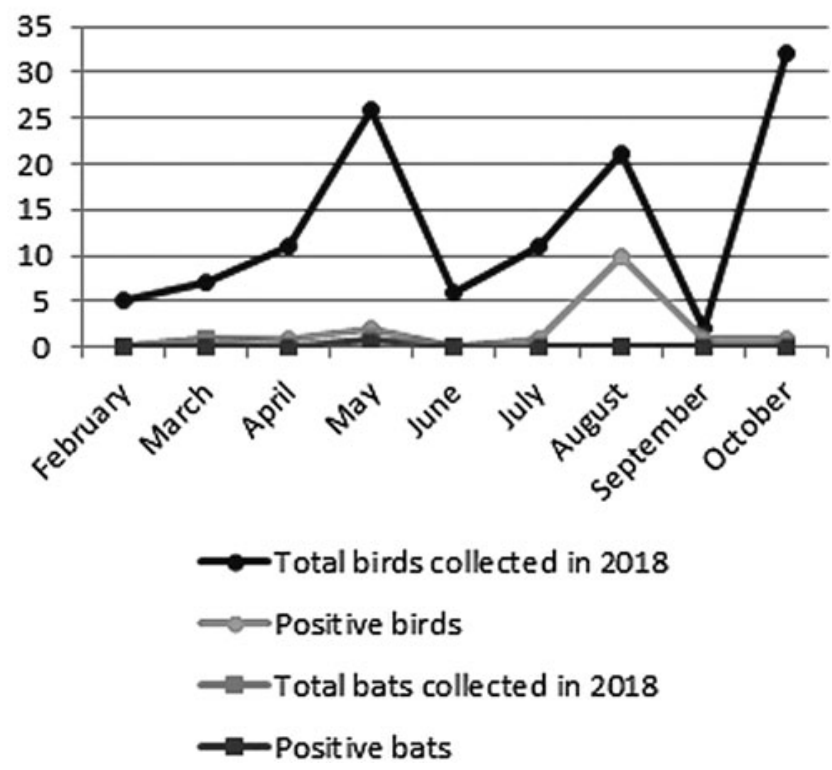

FIG. 1. Number of collected and USUV-positive dead birds and bats during seasonal outbreaks in southern Belgium in 2017 (A) and 2018 (B). USUV, Usutu virus. 
Table 2. Summary of Macroscopic and Microscopic Findings Observed in Usutu Virus-Infected Birds

\begin{tabular}{|c|c|c|c|c|c|c|c|}
\hline & Blackbird & $\begin{array}{c}\text { Egyptian } \\
\text { goose }\end{array}$ & $\begin{array}{c}\text { Eurasian } \\
\text { jay }\end{array}$ & $\begin{array}{c}\text { House } \\
\text { sparrow }\end{array}$ & $\begin{array}{c}\text { Eurasian } \\
\text { magpie }\end{array}$ & $\begin{array}{c}\text { Tawny } \\
\text { owl }\end{array}$ & $\begin{array}{l}\text { Song } \\
\text { thrush }\end{array}$ \\
\hline \multicolumn{8}{|l|}{ Gross findings } \\
\hline \multicolumn{8}{|l|}{ Nutritional status } \\
\hline Good & $26 / 36$ & $2 / 2$ & $1 / 1$ & $2 / 2$ & $2 / 2$ & - & - \\
\hline Mild emaciation & $6 / 36$ & - & - & - & - & - & - \\
\hline Cachexia & $4 / 36$ & - & - & - & - & $1 / 1$ & $1 / 1$ \\
\hline Lung & Hemorrhage 5/36 & $\begin{array}{l}\text { Fibrinous } \\
\text { pneumonia }\end{array}$ & - & - & - & $\begin{array}{l}\text { Fibrinous } \\
\text { pneumonia }\end{array}$ & - \\
\hline Splenomegaly & 22/36 (2 atrophic) & $0 / 2$ & $1 / 1$ & $1 / 2$ & $1 / 2$ & $0 / 1$ & $0 / 1$ \\
\hline Hepatomegaly & $11 / 36$ & $0 / 2$ & $0 / 1$ & $0 / 2$ & $0 / 2$ & $0 / 1$ & $0 / 1$ \\
\hline Enteritis & $9 / 36$ & $0 / 2$ & $0 / 1$ & $0 / 2$ & $0 / 2$ & $0 / 1$ & $1 / 1$ \\
\hline \multicolumn{8}{|l|}{ Histological findings } \\
\hline Nonpurulent encephalitis & 25/36 (11/36 autolysis) & $0 / 1$ & $0 / 1$ & $0 / 2$ & $0 / 2$ & $0 / 1$ & - \\
\hline Myocardial necrosis & $21 / 36$ (6/36 autolysis) & $\begin{array}{c}1 \text { autolysis } \\
0 / 2\end{array}$ & $0 / 1$ & $0 / 2$ & $0 / 2$ & $0 / 1$ & - \\
\hline Pneumonia/hemorrhage & $14 / 36$ & $2 / 2$ & $0 / 1$ & $0 / 2$ & $0 / 2$ & $1 / 1$ & - \\
\hline Hepatitis/hepatonecrosis & 19/36 (9/36 autolysis) & $1 / 2$ & $0 / 1$ & $0 / 2$ & $0 / 2$ & $0 / 1$ & - \\
\hline Splenitis/necrosis & $17 / 36$ (9/36 autolysis) & $0 / 2$ & $1 / 1$ & $1 / 2$ & $1 / 2$ & $0 / 1$ & - \\
\hline Nephritis/tubular necrosis & $13 / 36$ (11/36 autolysis) & $0 / 2$ & $1 / 1$ & $0 / 2$ & $0 / 2$ & $0 / 1$ & - \\
\hline
\end{tabular}

Zealand), with representative USUV strains retrieved from GenBank. The phylogenetic tree was then constructed as described in Cadar et al. (2016). Complete genomic sequences of USUV strains isolated in cell culture in 2017 were obtained by multiple overlapping PCRs using 17 pairs of primers and Sanger sequencing as in Cadar et al. (2014). The full-length genome sequences were generated using Geneious v10.2.3. The consensus sequences were subsequently aligned with full-genome or polyprotein coding sequences of all USUV strains available in databases to evaluate specific variation within these new strains. Both the nucleotide and the deduced amino acid sequences were compared using Geneious v10.2.3.

\section{Results}

\section{Detection of USUV infection and pathological findings}

In total, 253 dead birds were collected in 2017 and 2018, of which $27.3 \%$ and $13.4 \%$ were found USUV positive by RTqPCR and pan-flavivirus RT-PCR, respectively (Table 1). Ten dead bats were tested for the presence of USUV RNA, two of which contained USUV RNA (one found in Namur in 2017 and the other in Liege in 2018). The latter also tested positive with the pan-flavivirus RT-PCR. The first positive case in 2017 was collected in April while that of 2018 was found 1 month earlier (Fig. 1). All the bats were tested RT-qPCR negative for the presence of Lyssavirus (data not shown).
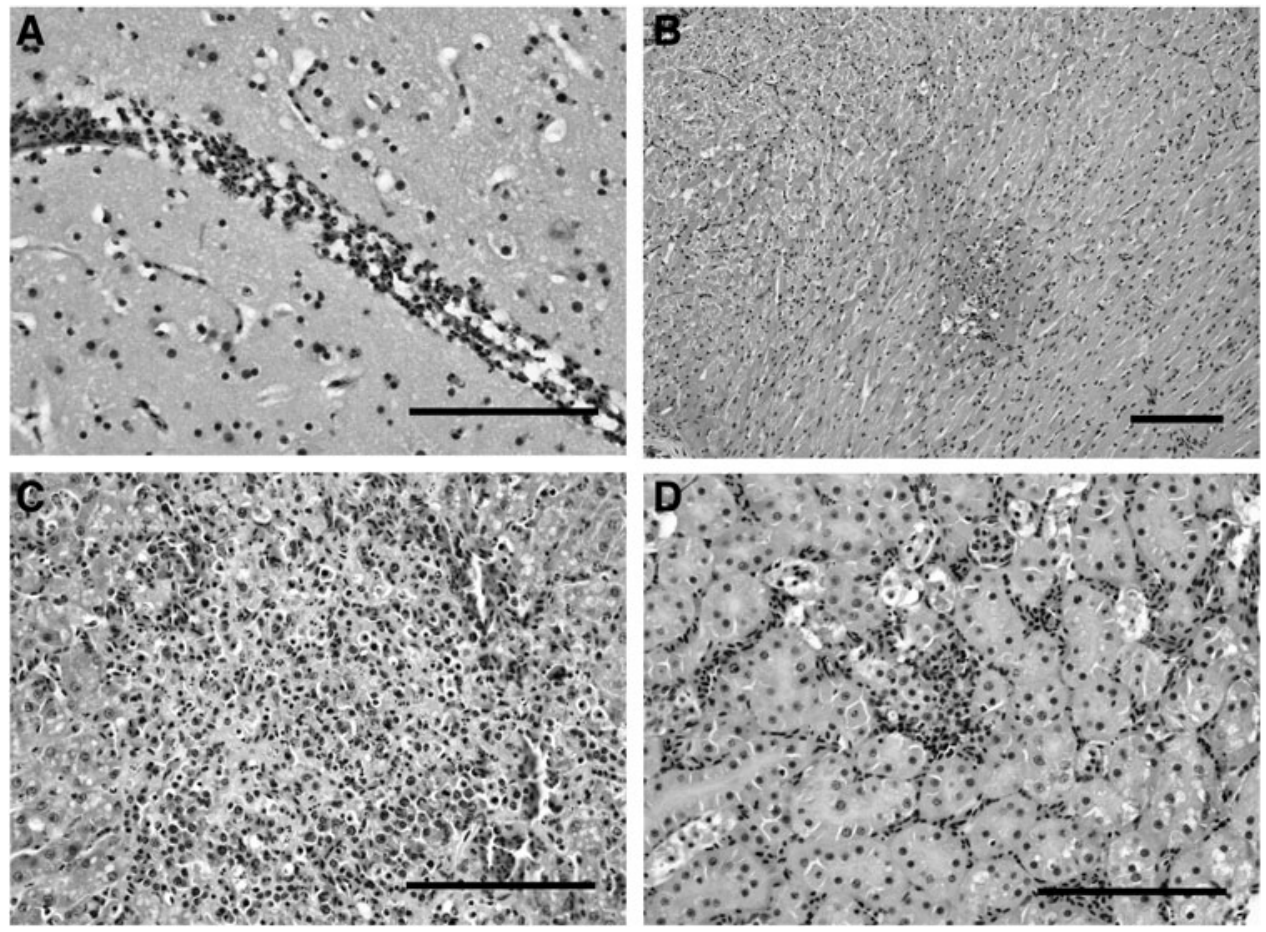

FIG. 2. Pathological findings in an USUV-positive blackbird dead in August 2017, hematoxylin and eosin, Scale bars: $50 \mu \mathrm{m}$. (A) Cerebral cortex, blackbird. Lymphocytic perivascular encephalitis. (B) Heart, blackbird. Myocardial necrosis with mild infiltration of heterophils and lymphocytes. (C) Liver, blackbird. Focal coagulative necrosis with massive heterophilic and lymphocytic infiltration. (D) Kidney, blackbird. Acute focal tubular necrosis with lymphocytic interstitial nephritis. 


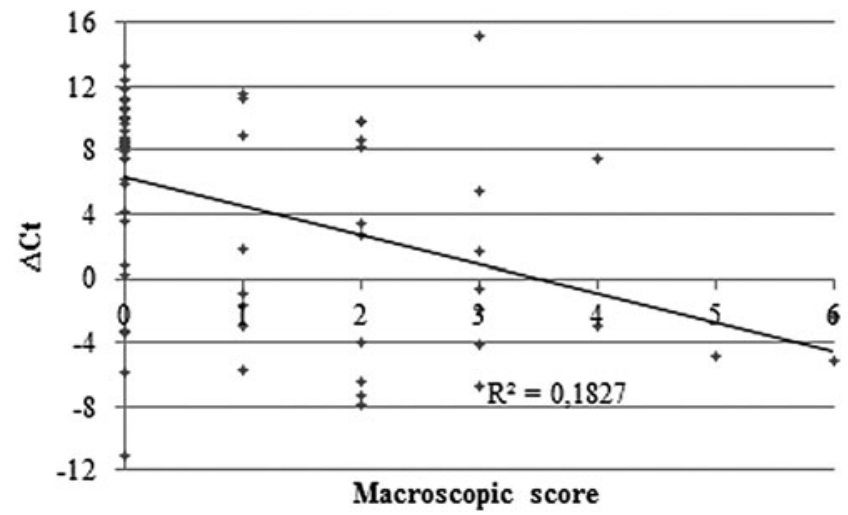

FIG. 3. Correlation between the relative amount of Usutu genomic RNA $(\Delta \mathrm{Ct}=\mathrm{Ct}$ sample $-\mathrm{Ct}$ of messenger RNA of beta-actin) and the macroscopic lesional score attributed to birds. $\mathrm{Ct}$, cycle threshold.

A complete necropsy could not be conducted in seven birds due to the autolytic status of the carcasses. Similarly, the microscopic analysis could not be performed in 37 $(53.6 \%)$ of the positive birds detected by RT-qPCR due to autolysis. Lesions observed in USUV-infected cases are summarized in Table 2 and shown in Fig. 2.

A low coefficient of correlation $\left(R^{2}=0.1827\right.$ and 0.1446 , respectively) was found between the relative abundance of viral genomes $(\Delta \mathrm{Ct})$ and the score of splenomegaly and hepatomegaly or the microscopic lesion scores, respectively (Fig. 3).

USUV was successfully isolated from fresh liver and brain tissues of four blackbirds collected in August 2017, all found in the province of Liege (Seraing, Grivegnee, Villers-auxtours, and Richelle) and each of these strains were named accordingly. No virus isolates were obtained from dead birds in 2018.
The IHC revealed the presence of USUV antigens in the brain, heart, lung, liver, kidney, and spleen of four blackbirds, which were necropsied shortly after death and another blackbird stored at $-20^{\circ} \mathrm{C}$ before necropsy (Fig. 4).

The labeled cells corresponded to degenerate neurons, cardiomyocytes, pneumocytes, renal tubular cells, enterocytes, endothelial cells in the spleen, lymphocytes, and macrophages.

\section{Genetic characterization of the detected USUV strains}

The amplicons obtained with the pan-flavivirus RT-PCR (partial gene sequences coding for the NS5 protein) were submitted to GenBank (MK230894-MK230924). Phylogenetic analysis showed that most Belgian strains belong to Europe 3 lineage and some to Africa 3 lineage (Fig. 5). Besides, one strain, detected in a common chaffinch (Fringilla coelebs), was clustered in Europe 1 lineage.

Full-genome sequences of the four USUV strains isolated in cell culture were successfully obtained: Villers/2017 (Genbank: MK230890), Seraing/2017 (Genbank: MK230892), Richelle/2017 (Genbank: MK230893), and Grivegnee/2017 (Genbank: MK230891). The first three strains revealed to be in Europe 3 lineage, while the fourth was classified in Africa 3 lineage (Fig. 4).

The genetic distance calculated with the complete nucleotide sequence between the four strains ranged between $97.1 \%$ and $99.6 \%$. At the amino acid level, the strains Villiers/2017 and Seraing/2017 were almost identical $(99.9 \%$, 5 amino acid substitutions) and showed $\sim 99.0 \%$ of similarity with Richelle/2017 and Grivegnee/2017 (for more details, see Supplementary Tables S1 and S2).

Comparative analysis of the four USUV isolates with all USUV sequences available in the databases revealed 3 unique silent mutations in Villers/2017, 4 in Grivegnee/ 2017 and Richelle/2017, and 10 others in Seraing/2017. A few substitutions resulted in unique changes in amino acid
FIG. 4. Immunohistochemical labeling of USUV antigens, natural infection with USUV, Blackbird. Mayer hematoxylin counterstain, scale bars: $50 \mu \mathrm{m}$. Staining in antigen-positive cells from the heart (A), lung (B), liver (C), and small intestine (D).
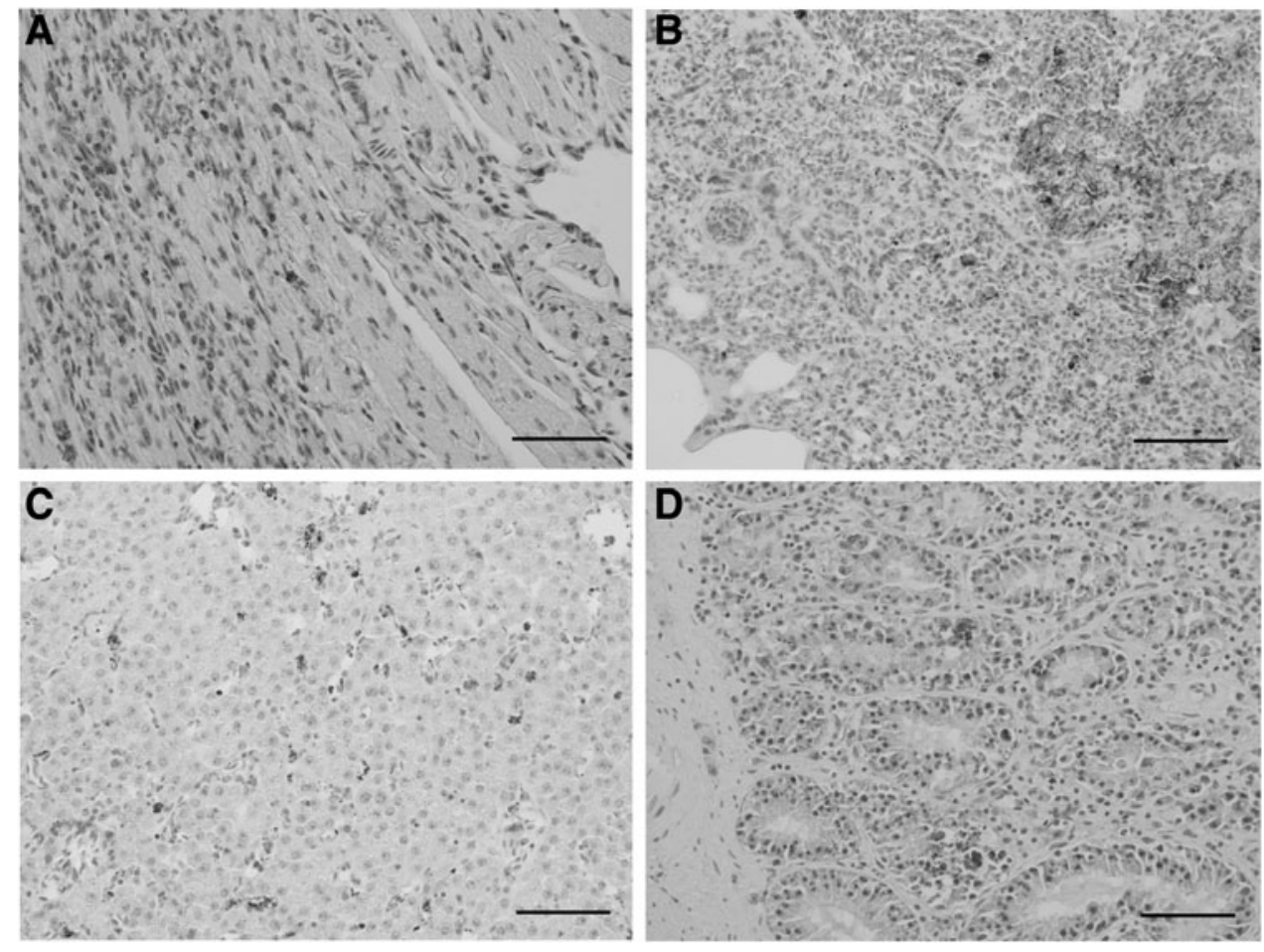


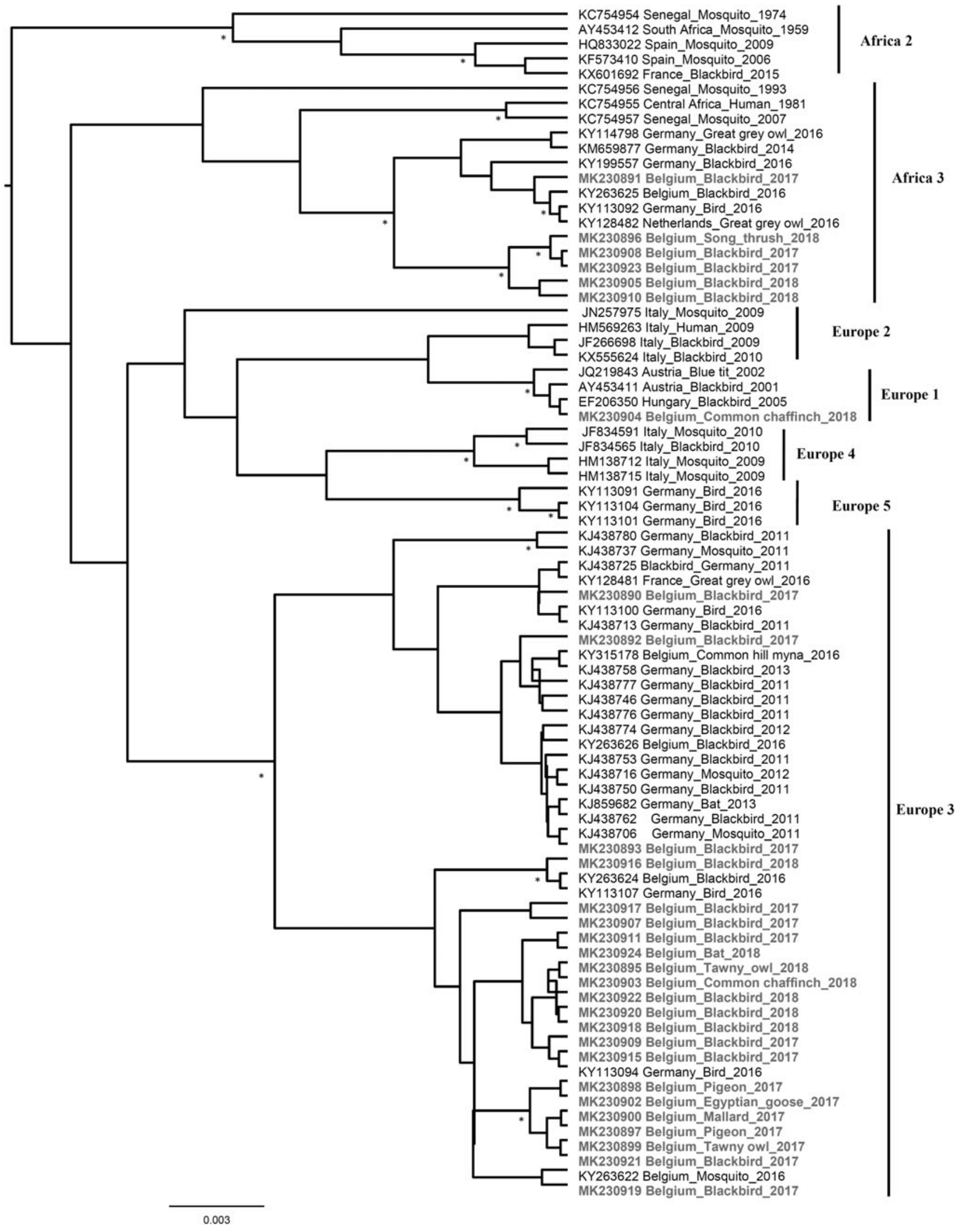

FIG. 5. Phylogenetic tree of USUV variants circulating in wild birds and bats, Belgium, 2017-2018. The tree is based on the partial NS5 gene and shows the placement of USUV variants that were detected during the surveillance period in comparison with representative USUV sequences from GenBank. Statistical supports of grouping from Bayesian posterior probabilities (clade credibilities $\geq 90 \%$ ) are indicated at the nodes with asterisks. To improve visualization, Africa 1 lineage (KC754958 Central African Republic_Mosquito_1969) is not represented in the figure, and phylogenetic positions of the newly USUV detected strains are bold. Taxon information includes the GenBank accession number, isolation/detection year, and country in which the virus was detected. Scale bar indicates the mean number of nucleotide substitutions per site. 
residues of Seraing/2017 (K1576R and G2325I), Richelle/ 2017 (T369M), and Grivegnee/2017 (S125F and M2094I) (for details, see Supplementary Table S3).

\section{Discussion}

USUV is an emerging mosquito-borne flavivirus highly pathogenic to several wild bird species. After its emergence in Italy in 1996 (Weissenböck et al. 2013), it has spread to several European countries, including Belgium in 2012, where it re-emerged in 2016 (Cadar et al. 2016, Borm et al. 2017, Garigliany et al. 2017, Rouffaer et al. 2018). In this study, we show that USUV infection in wild birds occurred in southern Belgium during the two subsequent years (2017-2018). In addition, the virus was detected in overwintering $C$. pipiens pools collected in 2016 by RT-qPCR (Cadar et al. 2016) and in bats in 2017 and 2018. Together, these findings highly suggest that USUV has managed to establish a transmission cycle between local bird, bat, and mosquito species and to overwinter in affected areas, where it is becoming endemic.

USUV infections were detected in $>90$ bird species belonging to 35 families, but massive die-offs were mainly reported in blackbirds and great gray owls (Strix nebulosa) (Benzarti et al. 2019). In this study, more than half of the RT-qPCR-positive cases were blackbirds. Hepatomegaly, splenomegaly, necrotizing and nonsuppurative inflammation in these tissues were indicative of a viral disease but without correlation to the abundance of the virus within the tissues. Many hypotheses can explain this observation, such as the poor preservation of viral RNA, the difference in the stages of infection (Lecollinet et al. 2016), or the occurrence of a simultaneous fatal infection with other pathogens. USUV RNA was found in a series of new bird species, namely the Egyptian goose (Alopochen aegyptiaca), mallard duck (Anas platyrhynchos), common swift (Apus apus), common chaffinch (F. coelebs), Eurasian wren (Troglodytes troglodytes), tawny owl (Strix aluco), and white wagtail (Motacilla alba). The mere presence of USUV RNA does not mean that the virus infection was the cause of death (Savini et al. 2011). Pathognomonic lesions and USUV antigen were not observed in these birds, and this may indicate a simple portage or a hyperacute infection (Lecollinet et al. 2016). These species might nevertheless play a role in the transmission cycle of the virus. The potential pathogenicity of USUV for these species, in particular the development of virulence in Anatidae, deserves further investigations.

The pan-flavivirus surveillance using conventional RTPCR demonstrated that no other flavivirus than USUV is circulating in birds and bats from Belgium. Such surveillance is very important for monitoring the possible introduction of WNV, which is endemic in many southern, eastern, and central European countries and has recently emerged in Germany in birds and horses (Lühken et al. 2019).

Phylogenetic analysis revealed the reoccurrence of the same or closely related USUV strains in southern Belgium during three consecutive years, and supports the endemization of these strains rather than their constant introduction each season. The potential role of Pipistrellus bats in the overwintering of the virus and in the epidemiological cycle of USUV as amplifying host was suggested (Cadar et al. 2014) and here sustained by the detection of bat-derived strains phylogenetically similar to the strains circulating in birds in
Belgium. In the meantime, ongoing introduction events of USUV are demonstrated in this study by the detection of a new USUV strain in 2018 from a common chaffinch, which was classified in Europe 1 lineage. The distribution of European 1 lineage strains was previously restricted to Austria, Hungary, and Serbia. While in Austria the circulation of viruses from this lineage has not been reported since 2005 (Chvala et al. 2007), virus activity of European 1 lineage strains has been described in Hungary in 2005, 2010, 2011, and 2015 (Bakonyi et al. 2017a) and lineage expansion to Serbia was detected in 2014 (Kemenesi et al. 2018). The introduction route of USUV Europe 1 lineage strain in Belgium is unclear. Mechanisms such as bird migration (Engel et al. 2016), international bird trade, or mosquitoes dispersal could be involved (Ziegler et al. 2016).

Finally, due to its increasingly recognized zoonotic potential and to our data of USUV continuous circulation, public health authorities and physicians in Belgium should be aware of the risk of USUV infection in humans and include this virus in their differential diagnosis of neurological disease. Continuous monitoring of bird deaths combined with serological studies in wild birds and other vertebrate hosts of USUV should be conducted in Belgium with the aim to keep track of the virus evolution, to fully understand the virus dynamics, and to provide an early prediction of human infections.

\section{Acknowledgments}

The authors gratefully acknowledge the scientific staff of the Surveillance Network for Wildlife Diseases, the forest rangers of the "Nature and Forests" department (SPW) of the Walloon Region, and all birdwatchers and wildlife lovers for their enthusiasm and the time they have dedicated to search for diseased birds on the field first, then to deliver them to the University of Liège Faculty of Veterinary Medicine facilities.

\section{Authors' Contributions}

E.B. and M.G. conceived and designed the study; A.L., D.D., and M.F. collected samples; E.B. performed autopsy; E.B., M.S., and M.F. performed laboratory experiments; E.B., M.G., D.C., J. S.-C., and J.R. performed data analysis; E.B. and M.G. wrote the article. All authors reviewed the article.

\section{Author Disclosure Statement}

No conflicting financial interests exist.

\section{Funding Information}

This work was partly supported by the Research Council in Life Sciences of the University of Liège and by the Fonds de la Recherche Scientifique-FNRS under grant no. J.0069.19.

\section{Supplementary Material}

Supplementary Table S1

Supplementary Table S2

Supplementary Table S3

\section{References}

Bakonyi T, Erdélyi K, Brunthaler R, Dán Á, et al. Usutu virus, Austria and Hungary, 2010-2016. Emerg Microbes Infect 2017a; 6:e85. 
Bakonyi T, Erdélyi K, Ursu K, Ferenczi, E, et al. Emergence of Usutu virus in Hungary. J Clin Microbiol 2007; 45:3870 3874.

Bakonyi T, Jungbauer C, Aberle SW, Kolodziejek J, et al. Usutu virus infections among blood donors, Austria, July and August 2017-Raising awareness for diagnostic challenges. Euro Surveill 2017b; 22. pii: 17-00644.

Becker N, Jost H, Ziegler U, Eiden M, et al. Epizootic emergence of Usutu virus in wild and captive birds in Germany. PLoS One 2012; 7:e32604.

Benzarti E, Linden A, Desmecht D, Garigliany M. Mosquitoborne epornitic flaviviruses: An update and review. J Gen Virol 2019; 100:119-132.

Cadar D, Becker N, Campos Rde M, Börstler J, et al. Usutu virus in bats, Germany, 2013. Emerg Infect Dis 2014; 20: 1771-1772.

Cadar D, Lühken R, van der Jeugd H, Garigliany $\mathrm{M}$, et al. Widespread activity of multiple lineages of Usutu virus, western Europe, 2016. Euro Surveill 2016; 22. pii: 30452.

Cavrini F, Gaibani P, Longo G, Pierro A, et al. Usutu virus infection in a patient who underwent orthotropic liver transplantation, Italy, August-September 2009. Euro Surveill 2009; 14. pii: 19448.

Chvala S, Bakonyi T, Bukovsky C, Meister T, et al. Monitoring of Usutu virus activity and spread by using dead bird surveillance in Austria, 2003-2005. Vet Microbiol 2007; 122: 237-245.

Diagne MM, Henriette M, Ndione D, Paola N Di, et al. Usutu Virus Isolated from Rodents in Senegal. Viruses 2019; 11. pii: E181.

Durand B, Haskouri H, Lowenski S, Vachiery N, et al. Seroprevalence of West Nile and Usutu viruses in military working horses and dogs, Morocco, 2012: Dog as an alternative WNV sentinel species? Epidemiol Infect 2016; 144: 1857-1864

Eiden M, Gil P, Ziegler U, Rakotoarivony I, et al. Emergence of two Usutu virus lineages in Culex pipiens mosquitoes in the Camargue, France, 2015. Infect Genet Evol 2018; 61:151154.

Engel D, Jöst H, Wink M, Börstler J, et al. Reconstruction of the evolutionary history and dispersal of Usutu virus, a neglected emerging arbovirus in Europe and Africa. MBio 2016; 7: e01938-15.

García-bocanegra I, Paniagua J, Gutiérrez-guzmán AV, Lecollinet S, et al. Spatio-temporal trends and risk factors affecting West Nile virus and related flavivirus exposure in Spanish wild ruminants. BMC Vet Res 2016; 12:249.

Garigliany M, Linden A, Gilliau G, Levy E, et al. Usutu virus, Belgium, 2016. Infect Genet Evol 2017; 48:116-119.

Garigliany MM, Marlier D, Tenner-Racz K, Eiden M, et al. Detection of Usutu virus in a bullfinch (Pyrrhula pyrrhula) and a great spotted woodpecker (Dendrocopos major) in North-west Europe. Vet J 2014; 199:191-193.

Hassine BT, Massis De F, Calistri P, Savini G, et al. First detection of co-circulation of West Nile and Usutu viruses in equids in the South-west of Tunisia. Transbound Emerg Dis 2014; 61:385-389.

Jöst H, Bialonski A, Maus D, Sambri V, et al. Isolation of Usutu virus in Germany. Am J Trop Med Hyg 2011; 85:551553.

Kaic B, Barbic L, Lesnikar V, Listes E, et al. First evidence of simultaneous occurrence of West Nile virus and Usutu virus neuroinvasive disease in humans in Croatia during the 2013 outbreak. Infection 2014; 42:689-695.
Kemenesi G, Buzás D, Zana B, Kurucz K, et al. First genetic characterization of Usutu virus from Culex pipiens mosquitoes Serbia, 2014. Infect Genet Evol 2018; 63:58-61.

Kuno G, Chang GJ, Tsuchiya KR, Karabatsos N, et al. Phylogeny of the genus Flavivirus. J Virol 1998; 72:73-83.

Lecollinet S, Blanchard Y, Manson C, Lowenski S, et al. Dual emergence of Usutu virus in common blackbirds, Eastern France, 2015. Emerg Infect Dis 2016; 22:2225-2227.

Lühken R, Keller M, Cadar D, Grinten E Van Der, et al. West Nile virus epizootic in Germany, 2018. Antiviral Res 2019; 162:39-43.

Mannasse B, Mendelson E, Orshan L, Mor O, et al. Usutu virus RNA in mosquitoes, Israel, 2014-2015. Emerg Infect Dis 2017; 23:1699-1702.

Nikolay B, Diallo M, Bouh Boye CS, Alpha Sall A. Usutu virus in Africa. Vector Borne Zoonotic Dis 2011; 11:1417-1423.

Pecorari M, Longo G, Gennari W, Grottola A, et al. First human case of Usutu virus neuroinvasive Infection, Italy, AugustSeptember 2009. Euro Surveill 2009; 14. pii: 19446.

Percivalle E, Sassera D, Rovida F, Isernia P, et al. Usutu virus antibodies in blood donors. Vector Borne Zoonotic Dis 2017; 17:658-661.

Pierro A, Gaibani P, Spadafora C, Ruggeri D, et al. Detection of specific antibodies against West Nile and Usutu viruses in healthy blood donors in northern Italy, 2010-2011. Clin Microbiol Infect 2013; 19:E451-E453.

Rouffaer LO, Steensels M, Verlinden M, Vervaeke M, et al. Usutu virus epizootic and plasmodium coinfection in Eurasian Blackbirds (Turdus merula) in Flanders, Belgium. J Wildl Dis 2018; 54:859-862.

Savini G, Monaco F, Terregino C, Di Gennaro A, et al. Usutu virus in Italy: An emergence or a silent infection? Vet Microbiol 2011; 151:264-274.

Simonin Y, Sillam O, Carles MJ, Gutierrez S, et al. Human Usutu virus infection with atypical neurologic presentation, Montpellier, France, 2016. Emerg Infect Dis 2018; 24:875-878.

Van Borm S, Lambrecht B, Vandenbussche F, Steenselsb M. Complete coding sequence of Usutu Belgium/2016 obtained from the brain tissue of an infected captive Common Hill Myna (Gracula religiosa). Genome Announc 2017; 5. pii: e00042-17.

Weissenböck H, Bakonyi T, Rossi G, Mani P, et al. Usutu virus, Italy, 1996. Emerg Infect Dis 2013; 19:274-277.

Weissenböck H, Kolodziejek J, Url A, Lussy H, et al. Emergence of Usutu virus, an African mosquito-borne flavivirus of the Japanese encephalitis virus group, Central Europe. Emerg Infect Dis 2002; 8:652-656.

Ziegler U, Fast C, Eiden M, Bock S, et al. Evidence for an independent third Usutu virus introduction into Germany. Vet Microbiol 2016; 192:60-66.

Address correspondence to: Prof. Mutien Garigliany Fundamental and Applied Research for Animals \& Health (FARAH) Faculty of Veterinary Medicine University of Liège Sart Tilman B43 B-4000 Liège Belgium

E-mail: mmgarigliany@uliege.be 